Journal of Learning and Development Studies (JLDS)

DOI: $10.32996 /$ jlds

Journal Homepage: www.al-kindipublisher.com/index.php/jlds

\title{
Modular Learning: Struggles and Coping Mechanisms of Mothers Not Speaking Mother Tongue
}

Tricia B. Dealagdon

College of Teacher Education, Western Mindanao State University, Zamboanga City, Philippines

Corresponding Author: Tricia B. Dealagdon, E-mail: triciabarcelodealagdon@gmail.com

\section{ARTICLE INFO}

Received: August 15, 2021

Accepted: September 25, 2021

Volume: 1

Issue: 1

DOI: $10.32996 / j$ lds.2021.1.1.8

\section{KEYWORDS}

Modular learning, mother tongue, Mother Tongue Based-

Multilingual Education

\section{ABSTRACT}

Modular learning is the current learning modality of primary education in the Philippines where traditional teacher-student practice has now been shifted to motherchild since mothers are the immediate assistants of their child in modular learning. Therefore, they play essential parts in their children's education. More so, this learning modality is applicable in all given subjects, including the Mother Tongue (MT). Whereas MT modules will be solely assisted by mothers regardless of the mothers' MT. The objective of this study is to determine the struggles and coping mechanisms of mothers not speaking the MT in assisting their child in the MT subject. Moreover, this study utilized a qualitative-descriptive design which included semi-structured interview. More so, purposive sampling was utilized to determine the respondents of this study. The total number of respondents is 10 and are all mothers. The respondents' age ranged between 24-35 years old. It was discovered from the interviews that difficulty in understanding Chavacanowords on the module, difficulty in comprehending instructions on the module, lack of educational pictures, difficulty in translating to the child's Mother Tongue, difficulty in facilitating learning, difficulty managing child's behavior and struggle in implementing time management became their primary struggles in assisting their child in the MT subject. It is also important to note that mothers were still able to assist their child despite of these challenges through seeking assistance from native Chavacanospeakers, from someone who has more knowledge in Chavacano, from the teacher, using the translation provided as reference, searching on the internet, repetitive teaching, practice through conversation, involvement during discussions, translating Chavacano to their mother tongue, materials from the teacher, recording of classes, use of infographics, providing positive reinforcement and letting family members to assist.

Published by Al-Kindi Center for Research and Development, London, United Kingdom. Copyright (c) the author(s). This open access article is distributed under a Creative Commons Attribution (CC-BY) 4.0 license (https://creativecommons.org/licenses/by-nc-nd/4.0/)

\section{Introduction}

The pandemic has caused drastic changes at almost everything, including in education. A part of it is the transition from the faceto-face classes to various learning modalities such as modular learning. Modular learning is done through print materials that are composed of only decongested learning competencies and are being distributed to learners (De Villa \& Manalo, 2020). As a matter of fact, the Department of Education has been utilizing modular learning instead of the traditional face-to-face for education to not be jeopardized (Abante et al., 2021). This has been the most convenient way for learning to be continued despite the strict implementation of physical gathering.

The traditional "teacher-student" set-up has now put into halt. For generations, the practice of learning is done through the teacher speaking in front while learners sit and listen. However, modular learning is facilitated through print materials. This means that teachers are not the ones teaching the learners, instead, assistance from the learner's family member is a must- apparently, their mothers. Mothers are known to be their child's first teacher and the immediate person to assist the education of her child (Mazuru\&Nyambi, 2012). Moreover, mothers are most likely to provide assistance as it greatly impacts on their child's learning 
(Choi, Kang, Cho, \&Sheo, 2019). In other words, mothers are the ones facilitating learning through assistance in their child's modules.

The aforementioned shift applies in all subjects including in the Mother Tongue Based-Multilingual Education (MTB-MLE). MTBMLE was established through Department of Education (DepEd) Order No. 74, which mandates the use of Mother Tongue (MT) as the primary medium of instruction (Mol) from kindergarten to third grade. The ground seen is that learners can express themselves through the comfort of their MT in the classroom (Tupas \& Martin, 2016). This implies that effective learning may occur when learners' MT is being utilized as Mol as they can participate and share their ideas during class discussions. As a support, the studies of Dekker and Young (2005) and Nolasco, Datar and Azurin (2010) proved the effectiveness of the MT in delivering classroom instruction by showing overwhelming positive results compared to solely English as Mol. Continuing, there are only twelve languages or lingua franca that the DepEd identifies as Mol and one of which is Chavacanoas the Mol in Zamboanga City.

However, Zamboanga City, as a basin of different tribes and ethnicities, varies from language to language. In other words, learners have grown up in a household speaking other languages. Hence, they are being taught in Chavacano in which they are not yet fluent. As a result, the intended benefits of the MTB-MLE might not be attained by these learners (Abdon et al., 2020). This challenge can also be drawn in mothers not speaking the MT since they are the ones assisting their child's module in MTB-MLE during these times.

There are studies conducted with regard to MTB-MLE. Tupas (2015) found out that MTB-MLE became a challenge as it shows the inequalities of multilingualism. He explained that the MTB-MLE focused on the language that is used by the majority but however disregarded those languages from the minority. Thus, this states that not all learners have the same MT that is being identified as $\mathrm{Mol}$ in their classroom. As a matter of fact, Tupas (2016) stated that Romblomanon, as the language of Romblon, must be the Mol instead of Tagalog. The identified Mol of DepEd was not totally accepted by the Romblomanon. In a similar vein, parents from Zamboanga City exhibited limited positively with regard toChavacanoas Mol (Francisco et al., 2020). With regard to modular learning, Mazrekaj and De Witte (2019) suggested positive benefits of modular learning such as less dropout rate. However, De Villa and Manalo (2020) stated that modular learning is challenging as it requires time in printing and dividing conventional courses into smaller chunks called modules (Mazrekaj\& De Witte, 2019).

Observing the aforementioned studies, it can be noted that most of the studies focused on the general lenses of MTB-MLE toward parents and modular learning as a whole. However, none or limited research has examined the struggles and coping mechanisms in modular learning. The attitude of parents towards Chavacanoas Mol has been studied, however, this study was not aimed to determine the struggles and coping mechanisms of mothers in assisting their child in their MTB-MLE modules.

Therefore, the present study aims to close the gaps by determining the struggles and coping mechanisms of mothers, not speaking the Mother Tongue, in assisting their child in their MTB-MLE modules. The results significantly contribute to the effectiveness of modular learning specifically in the MT subject. To ensure that the objective is met, the study is guided by two research questions; (1) what are the struggles of mothers in assisting modular learning? and (2) what are the coping mechanisms of mothers in assisting modular learning?

\section{Modular Learning}

For ages, learning is facilitated through the traditional face-to-face setup where learners need to attend class in classrooms and teachers are the fore-facilitator of learning (Li, Qi, Wang, \& Wang, 2014). However, the outburst of Coronavirus Disease (also known as COVID-19) has placed the traditional educational system at an impasse (Senthilkumar\& Kumari, 2020). It has totally suspended face-to-face learning engagements of learners and teachers within the school. Apparently, education was put into halt.

The pandemic has paved the way for the implementation of distance education and one of its modalities is modular learning. De Villa and Manalo (2020) define modular learning as the division of conventional courses into smaller chunks which are called modules. These modules are composed of only decongested learning competencies and are being distributed to learners (De Villa \& Manalo, 2020). This learning modality has been used in primary and secondary education in the Philippines. According to a survey conducted by DepEd, modular learning has been the most preferred distance learning method of parents who have children enrolled in this academic year (Bernardo, 2020). The ground view is that learning through print and digital materials are the most convenient and budget wise learning modality at this time. Additionally, this modality addresses the concern of the learners from rural areas where internet connection is inaccessible for online learning (Dangle \&Sumaoang, 2020). Moreover, these modules are either delivered to the learner's parents or guardians through the Local Government Unit (LGU) or are distributed to parents in schools. Modular learning encourages learners to acquire independently and progress responsibility in answering tasks from the modules. 
However, there must be no or limited assistance from anyone, apparently from the household, to guide the progress of the learners (Dangle \&Sumaoang, 2020). Thus, determining the struggles and coping mechanisms assisting the child's modules is timely and significant; hence, this study.

\subsection{Mothers as their child's immediate assistant}

Since learning is inaccessible within the school, teachers need to team-up with the parents for the child's education. Therefore, parents play a vital role in this learning modality as they guide their children in their modules (FlipScience, 2020).

Thus, mothers are most likely to take this role. As a support, Mazuru and Nyambi (2002) claimed that mothers are the immediate person to assist the learning of their child as their assistance greatly impacts on their child's learning (Choi, Kang, Cho, \&Sheo, 2019). This means that mothers are the ones teamed up with teachers in assisting the learners in modular learning. In a similar vein, Bünning, Hipp and Munnes (2020) revealed that mostly mothers adjusted their working time to assist their child. Thus, they became the facilitators of learning through assisting their child in accomplishing their modules. Therefore, mothers have the greatest and essential role in the child's education regardless of the learning modalities (Siv \& Kim, 2019). Thus, mothers were given significance as well in this study.

\subsection{Mothers' struggles and coping mechanisms}

Mothers, as the immediate assistant, experience unprecedented challenges that are brought by the shift of learning modality. To support this claim, Bujard (2020) found out that mothers struggle in caring and assisting their child in the current learning modality that the pandemic has driven. Additionally, mothers are affected with the increasing care task that they need to portray which decreases their work time (Allmendinger, 2020). In other words, the time that must be spent by the mothers at work is now affected by their role in assisting their children. Moreover, Jellen and Ohlbrecht (2020) noted that mothers have encountered disadvantages with regard to emotional, performance and work-related aspects. Mothers are affected not only with regard to their work but also their emotional and performance as a mother.

The aforementioned studies show that mothers struggle in assisting their child in these times, narrowing to modular learning. In this study, mother's struggles, as well as coping mechanisms, were given importance as well.

\subsection{Mother Tongue Education}

The Philippines is composed of 181 spoken languages all throughout the country (Lewis, Simons, \&Fennig, 2013), the Department of Education (DepEd) has advanced the idea of Mother Tongue Based- Multilingual Education (MTB-MLE). MTB-MLE was established through Department of Education (DepEd) Order No. 74, which mandates the use of Mother Tongue (MT) as the primary medium of instruction (Mol) from kindergarten to third grade. There were 12 languages and lingua franca that the DepEd recognizes as Mol under the MTB MLE program. These are Tagalog, Cebuano, Maguindanaoan, Iloko, Bikol, Meranao, Kapampangan, Bahasa Sug(Tausug), Pangasinense, Hiligaynon, Waray, including Chavacano. The language policy aims to develop a child's proficiency in English and Filipino by addressing the child's Mother Tongue (MT) which he needs to learn and identify (Alieto, Devanadera, \&Buslon, 2019).

Thus, utilizing the child's MT as Mol is adhered to the MTB-MLE. Moreover, learners can freely express their thoughts with the usage of their MT in the class discussions (Tupas \& Martin, 2016). If learners can express themselves in the classroom, effective learning may occur. The studies of Dekker and Young, 2005 and Nolasco, Datar and Azurin, 2010 support this claim. Their studies proved the effectiveness of the MT in delivering classroom instruction by showing overwhelming positive results compared to solely English as Mol. Thus, it cannot be denied that the language chosen to be the Mol might not be the MT of some learners. According to Tupas (2015), MTB-MLE has chosen the language of the majority yet disregards those languages from the minority. It can be drawn that the recognized Mol might not be the learner's MT. As a proof, Romblomanon, the people of Romblon, did not totally accept Tagalog as their Mol. They claimed that Romblomanonmust be the Moldue to the fact that it is their local language. It might trigger difficulties not only to learners, but also to mothers who are the ones assisting their child's modules in this time; hence, this study.

\section{Method}

\subsection{Research Design}

The current research aims to determine the struggles and coping mechanisms of mothers who do not speak the Mother Tongue. Thus, the study follows a qualitative-descriptive design, which includes semi-structured interviews. This is a method-based inquiry that comprises interpretation of phenomena to comprehend how people make implications from their experiences (Denzin $\&$ Lincoln, 1994). This approach allows the researcher to gain a comprehensive understanding of a particular phenomenon (Yin, 2015 as cited in Nughoro, llimiani\& Rekha, 2020). In the context of this study, the mothers' struggles and coping mechanisms in assisting 
their child's MTB-MLE were analyzed by following this approach. Harding (2018) claimed that the contextualization of data is an important aspect.

\subsection{Participants}

Purposive sampling was utilized to determine the respondents of this study. Moreover, inclusion criteria were set to ensure that the respondents carry out the appropriate information for the objectives to be achieved, and these are as follows; (1) the respondent must be a mother of a kindergarten, grade one, two or three pupil, (2) the respondent must be the one assisting her child's module, and (3) the respondent must not be a native speaker of Chavacano. The study involved ten (10) respondents who are all mothers. Furthermore, the respondents' age ranged between 24-35 years old and are all residing in Zamboanga City. Moreover, the respondents' ethnicity is equally divided between Visayanand Tausug.

\subsection{Instruments and Data Collection}

The study employed a semi-structured interview that was developed by the researcher that is aligned to the research questions to attain the needed data. Harding (2018) stated that semi-structured interview's main advantage is that it allows new questions and ideas during the interview. Henceforth, this was implied in this research. More so, the instrument was validated by a Doctor of Philosophy in English Language Teaching and was administered for pilot testing to two mothers who did not take part of the ten (10) final participants. The interviews were conducted through phone calls since face-to-face interviews were restricted as part of the government's health protocol. Furthermore, the interviews were recorded through audio recording and were transcribed for data analysis. The researcher sought ethical approval and consent from the respondents before the collection of data.

\subsection{Method of Analysis}

The current study utilizes thematic analysis in analyzing the gathered data. Moules, Norrise, Nowell and White (2017) claimed that thematic analysis is a qualitative research method that can be employed across varied epistemologies and research queries. As a matter of fact, it is an effective method for analyzing respondents' responses (Clarke, 2006; King, 2004 as cited in Moules, Norris, Nowell \& White, 2017).

\section{Results and Discussions}

This section presents the results of data analysis with regard to the two research questions about struggles and coping mechanisms of mothers not speaking MT in modular learning.

Table 1: Struggles encountered by mothers

\begin{tabular}{|c|c|}
\hline Themes & Excerpts \\
\hline 1. Difficulty in understanding Chavacanowords on the module & $\begin{array}{l}\text { "...I sometimes do not understand some words..." } \\
\text { (Participant 1) } \\
\text { "I am really struggling... we are Tausug ... To be honest,I don't } \\
\text { understand all their words. As in nothing..." (Participant 2) } \\
\text { "...which I really find difficult since I do not know how to } \\
\text { speak Chavacano...I have difficulty with words... There are a } \\
\text { lot of strange words which are very much unfamiliar to me" } \\
\text { (Participant 3) } \\
\text { "I personally am not a Chavacano speaker... So while } \\
\text { teaching her the Mother Tongue subject which is a little bit } \\
\text { challenging... Why is it challenging? First of all because we } \\
\text { are not Chavacano speakers...there are deep Chavacano } \\
\text { words, especially traditional Chavacano words that I really } \\
\text { don't understand." (Participant 4) } \\
\text { ".I don't know how to speak Chavacano... so I am having a } \\
\text { hard time teaching him..." (Participant 5) }\end{array}$ \\
\hline
\end{tabular}




\begin{tabular}{|c|c|}
\hline & $\begin{array}{l}\text { "...I can't really understand some because the Chavacano } \\
\text { words in the Mother Tongue are deep... the other words are } \\
\text { difficult and incomprehensible..." (Participant 6) } \\
\text { "I am struggling because I do not know Chavacano } \\
\text { because I am a Muslim, we are Tausug."(Participant 7) } \\
\text { "...It's difficult especially in their Mother Tongue (subject) } \\
\text { which is Chavacano...so we, Tausug, are having a hard } \\
\text { time in Chavacano..." (Participant 8) } \\
\text { "...We've only been here in Zamboanga for about one year ... I } \\
\text { still don't know how to speak Chavacano... I was stressed } \\
\text { because I really don't understand"(Participant 10) }\end{array}$ \\
\hline 2. Difficulty in comprehending instructions on the module & $\begin{array}{l}\text { "...I also do not understand the directions." (Participant 1) } \\
\text { "For example, the activity is to color objects ...I cannot } \\
\text { understand the instructions..." (Participant 8) }\end{array}$ \\
\hline 3. Modules have no pictures as guide & $\begin{array}{l}\text { "...their modules are okay with pictures but if there are no } \\
\text { pictures, it's difficult." (Participant 4) }\end{array}$ \\
\hline 4. Difficulty in translating to the child's Mother Tongue & $\begin{array}{l}\text { "...it is challenging because I need to translate the lessons to } \\
\text { Tagalog for my child to understand..." (Participant 6) }\end{array}$ \\
\hline 5. Difficulty in facilitating learning & $\begin{array}{l}\text { "I don't know if my son understands or he just says yes, } \\
\text { because he can't pronounce well...I do not know if he } \\
\text { understands it or not. (Participant 1) } \\
\text { "They do not concentrate if we, parents, are the ones } \\
\text { teaching. When they cry, it's okay. Unlike in school, when } \\
\text { the teacher says "listen", they will really listen." (Participant } \\
\text { 2) } \\
\text { "...So even if I teach her multiple times to be familiarized, } \\
\text { he cannot still understand...Even if I'll repeat it multiple } \\
\text { times," (Participant 4) } \\
\text { "...If I read it, I just depend on the instructions. Seems to be } \\
\text { on my mind is "Is this the right instruction?" then I'll teach } \\
\text { my child what I have understood based on what I read." } \\
\text { (Participant 6) } \\
\text { "...The child's focus, because if the mother is the one } \\
\text { teaching, it's like a joke for them, unlike when the teachers } \\
\text { are the ones teaching." (Participant 9) }\end{array}$ \\
\hline
\end{tabular}


Table 1 presents the struggles encountered by mothers in assisting their child in their MT subject. There are seven occurring themes

\begin{tabular}{|c|c|}
\hline 5. Difficulty in facilitating learning & $\begin{array}{l}\text { "I don't know if my son understands or he just says yes, because he can't } \\
\text { pronounce well...I do not know if he understands it or not. (Participant 1) } \\
\text { "They do not concentrate if we, parents, are the ones teaching. When they } \\
\text { cry, it's okay. Unlike in school, when the teacher says "listen", they will } \\
\text { really listen." (Participant 2) } \\
\text { "...So even if I teach her multiple times to be familiarized, he cannot still } \\
\text { understand...Even if I'll repeat it multiple times," (Participant 4) } \\
\text { "...If I read it, I just depend on the instructions. Seems to be on my mind is } \\
\text { "Is this the right instruction?" then I'll teach my child what I have } \\
\text { understood based on what I read." (Participant 6) } \\
\text { "...The child's focus, because if the mother is the one teaching, it's like a } \\
\text { joke for them, unlike when the teachers are the ones teaching." (Participant } \\
9 \text { 9) }\end{array}$ \\
\hline 6. Difficulty in managing child's behaviour & $\begin{array}{l}\text { "The child, ma'am. They do not concentrate if we, parents, are the ones } \\
\text { teaching. When they cry, it's okay. Unlike in school..." (Participant 2) } \\
\text { "...it's a bit stressful because they are children...lt is difficult to let the child } \\
\text { answer in just one sitting..." (Participant 3) } \\
\text { "The child's focus, because if the mother is the one teaching, it's like a joke } \\
\text { for them, unlike when the teachers are the ones teaching." (Participant 9) }\end{array}$ \\
\hline $\begin{array}{l}\text { 7. Struggle in implementing time } \\
\text { management }\end{array}$ & $\begin{array}{l}\text { "...In my situation, I work Monday to Saturday, so I can only teach him in } \\
\text { his module in the evening but not totally everyday because sometimes I } \\
\text { can no longer teach him..."(Participant 1) } \\
\text { "...I 'm having a hard time...I am also a student, so I am also running out } \\
\text { of time to focus on them, therefore the child is also affected." (Participant } \\
\text { 5) } \\
\text { "...I'm asking for help from our neighbour to teach my child because } \\
\text { sometimes I am busy..." (Participant } 7 \text { ) } \\
\text { "It's difficult, ma'am, since I have work and I have to balance my time } \\
\text { between work and their module." (Participant 9) }\end{array}$ \\
\hline
\end{tabular}

which are presented. The participants provided seven struggles that they have encountered.

First, difficulty in understanding Chavacanowords on the module, nine (9) out of ten (10) or 90\% of the participants have encountered difficulties in understanding the modules utilizing Chavacano as theMol. The excerpt "I am really struggling...we are Tausug ... To be honest, I don't understand all their words. As in nothing..." provides evidence that participants have no understanding at any cost in the Chavacanolanguage and therefore cannot comprehend what was written in the child's MT module.

Participant 2 explained that having no understanding of the language results in no understanding of the module. In other words, the participant cannot understand any Chavacano words that are written in the modules. Moreover, participants 2, 7 and 8 stated 
that they struggle in assisting their child's module because of their ethnicity, particularly Tausug. They are not native speakers of Chavacano, therefore, they cannot comprehend the language most especially in the context of their child's MT subject.

Participants also experienced limited understanding of profound Chavacanowords. This is evident as four out of ten or forty percent (40\%) of the respondents shared the same. Participant 3 identified that there are a lot of profound Chavacano words that are unfamiliar to her. This challenge is also explained by participant 6, she also has difficulty in understanding some Chavacanowords which are deep. In other words, the deep Chavacanowords made it challenging for her to assist her child as it is difficult and incomprehensible. This means that the profound Chavacano words were not able to be comprehended by the mothers. Thus, it is a challenge for them in assisting their children in their MT modules.

Moreover, two out of ten or twenty percent (20\%) of the total participants expressed that they also struggled in comprehending instructions from the module.

The following excerpt supports the idea:

\title{
Participant 8
}

\author{
"For example, the activity is to color objects ... \\ I cannot understand the instructions \\ This, "nadiatunleksyonpinta con eldituyunatrabahousando", \\ I cannot really understand what this means, \\ that's why we have no answer here"
}

The participant explained that she struggled in understanding the instructions. She added that she can only understand the instruction if it is only a matching type. However, with the elaboration provided above, it can be probed that she cannot understand other than matching type. The difficulty in understanding instructions may lead to an unanswered module which basically means that mothers are not able to assist their child, as they cannot also comprehend the instructions.

The following excerpt also points this idea:

\section{Participant 1}

"I also do not understand the directions. Sometimes, I do not even let my child answer because I do not understand either."

One of the participants remarked that it is challenging if the modules have no pictures.

The following excerpt is supporting this idea:

\section{Participant 4}

\author{
"...their modules are okay with pictures
}

but if there are no pictures, it's difficult."

Furthermore, one out of the ten or $10 \%$ of the participants expressed that translating what was written in the module to her child MT is also a struggle. The excerpt "...it is challenging because I need to translate the lessons to Tagalog for my child to understand..." provides support that instead of directly assisting her child with the provided Mol, the participant needs to translate it first for her child to understand the lesson. Cummins (2000) posited that learners with strong MT language will be able to easily transfer and acquire learning through the use of the language. This means that translating the texts on the module to the child's MT will result in learners easily understanding the modules and eventually gain higher remarks. However, the process of translating became a struggle for a participant.

Participant 6 explained that it is challenging as it requires additional time to translate it. She added that it is more difficult when she also does not know what the word or lesson means, thus, she needs to look for the word first. Therefore, translating it to her child's MT is an extensive process; hence a struggle. 
More so, since modular learning is the current learning modality, parents, especially mothers, are the ones assisting their child regardless of their professions and jobs. Thus, five or $50 \%$ of the participants also encountered struggles in assisting as they lack teaching abilities.

The following excerpt supports this idea:

\title{
Participant 1
}

\author{
"I don't know if my son understands or he just says yes, \\ because he can't pronounce well... \\ I do not know if he understands it or not"
}

The participant expressed the uncertainty if her child learned or not. Mirroring it in the profession, there are types of assessment to ensure if the child learned and if the objectives are achieved. However, in the case of participant 1, she has not applied for an assessment to ensure that her child has learned something. Teachers, as the facilitator of learning, must possess an excellent teaching skill. It affects learners as it mirrors their improvements. In other words, teachers who have higher teaching skills than the average result in learners who will gain greater knowledge (Aaronson, Barrow, \& Sander, 2007). Brandsma and Knuver (1989), Kane and Staiger (2008) and Rockoff (2004) found out the same result in their studies. Therefore, possessing teaching skill in either teaching or assisting is a must in all modalities of learning. Hence, mothers are struggling with this concern.

In the case of participant 6, she uttered "If I read it, I just depend on the instructions. Seems to be on my mind is "Is this the right instruction?" then I'll teach my child what I have understood based on what I read". This excerpt also supports that this participant also encountered struggles in assisting as she lacked teaching abilities. Anzaldo (2021) stated that not all parents are knowledgeable in teaching their children. Thus, this becomes a struggle in the modular learning. In the education field, a blueprint of teaching which is called a lesson plan is a necessity. It served as a guide to teachers in teaching appropriately and effectively. However, it is not administered in this learning modality.

Moreover, participants also shared difficulties in handling their child's behavior while assisting them in their MT modules.

This excerpt is pointing this idea:

\section{Participant 3}

"...it's a bit stressful because they are children...

It is difficult to let the child answer in just one sitting..."

The participant claimed that she had a hard time assisting her child in one sitting or in one immediate command. She added that she needs to time it in her child's mood. In the cases of participants 2 and 9, they expressed that they also find difficulty in handling their children's behavior as their child's behavior is unlikely based on how they were in school.

The following excerpts are supporting this idea:

\section{Participant 2}

"The child, ma'am.

They do not concentrate if we, parents, are the ones teaching.

When they cry, it's okay.

Unlike in school..."

\section{Participant 9}

"The child's focus,

because if the mother is the one teaching,

it's like a joke for them,

unlike when the teachers are the ones teaching." 
The participants claimed that their children's behavior differs on how they behave in school. They have elaborated instances which they have encountered with regard to handling their children's behavior. Anzaldo (2021) suggested that parents should be more patient in assisting their children. Thus, it can be inferred that mothers cannot assist directly as they need to have authority first for their children to behave and to be ready for their modules.

The last struggle noted is the mother's time management. It has been noted that mothers realized how important their roles are in their child's education during this time (Anzaldo, 2021). The excerpts "It's difficult, ma'am, since I have work and I have to balance my time between work and their module" and "It's difficult, ma'am, since I have work and I have to balance my time between work and their module" prove that mothers have other loads and roles to take other than assisting their children. To support this claim, the study of Allmendinger (2020) revealed that due to the increase in child care, mothers' working time reduces and therefore must manage it well. Thus, time management is also a struggle they have experienced.

This excerpt also points out the claim:

\title{
Participant 5
}

\author{
"...I'm having a hard time...I am also a student, \\ so I am also running out of time to focus on them, \\ therefore the child is also affected."
}

The participant stated that she is having a hard time as she needs to balance her time as a student and as an assistant to her child's module. Thus, as a student, tons of activities and projects are mandatory, therefore, time and effort must be shared. As a result, time for assistance might decrease and the child's learning will be affected.

The following excerpt also supports this idea:

\section{Participant 7}

"I'm asking for help from our neighbour

to teach my child because sometimes I am busy..."

The participant reports that because of busy schedule, she was not able to assist her child anymore. She needs to attend work and therefore cannot give time to assist her child. In other words, she was not able to effectively manage her time between work and assisting her child.

Table 1.2: Coping mechanisms of mothers

\begin{tabular}{|c|c|}
\hline Themes & Excerpts \\
\hline \multirow[t]{8}{*}{$\begin{array}{l}\text { 1. Seeking assistance from native } \\
\text { Chavacanospeakers }\end{array}$} & $\begin{array}{l}\text { "... really need to ask help from my friends who know how to speak } \\
\text { Chavacano..." (Participant 2) }\end{array}$ \\
\hline & "...I first ask someone else who knows it." (Participant 3) \\
\hline & $\begin{array}{l}\text { "...So what I do is I ask some of my friends who are Chavacano speakers... I } \\
\text { ask my co-teachers who are teaching Mother Tongue." (Participant 4) }\end{array}$ \\
\hline & "I ask for help from the mother of his classmate, which I know." (Participant 5) \\
\hline & "...I chat with my co-mothers... just to ask for the definitions..." (Participant 6) \\
\hline & "...or ask someone what it means. I just ask questions." (Participant 7) \\
\hline & $\begin{array}{l}\text { "What I do is I call my friend to ask for assistance... I call my friends instead..." } \\
\text { (Participant 8) }\end{array}$ \\
\hline & $\begin{array}{l}\text { "... need to ask it to my aunt... ask her what is that and what is this." } \\
\text { (Participant 9) }\end{array}$ \\
\hline
\end{tabular}


2. Seeking assistance from someone "...I'm asking for help from our neighbour to teach my child... I do not know who has more knowledge in the Chavacano language..." (Participant 7)

Chavacano

"...some with the help of my husband... I ask help from my husband to answer"

(Participant 10)

"I ask my neighbours..." (Participant 10)

3. Seeking assistance from the teacher
"...I'll call their teachers to explain what it means... to know what I shall do and what I shall teach to the children..." (Participant 6)

4. Using the translation provided as reference "...there are translations which I can look over..." (Participant 3)

"There is also a translation from Chavacano to English there in the module..." (Participant 9)
"I sometimes do not understand some words so I research it... For me, I will research those difficult words..."(Participant 1)

"...I do research or I Google it...but in Spanish because there are no results if I search it in Chavacano..."... let him watch Chavacano videos on YouTube." (Participant 2)

"...Therefore, I have to Google it... My strategy is to search first..."(Participant 3)

"...what I do is to let him watch it on YouTube... so he could follow..." (Participant 5)

"I'll just do research... I looked it up on Google..." (Participant 7)

"We look for it on Google...We look for it on... We watch it on YouTube..." (Participant

6. Teaching the lessons repetitively

"...What I did is to teach and make him understand repetitively." (Participant 3)

"I'll repeat it multiple times..." (Participant 4)

"...I'll read it multiple times." (Participant 10)

7. Using Chavacanoas the language in casual conversation

"I speak Mother Tongue (Chavacano) to him... I train him here, even here at home, even not as part of his lecture." (Participant 1) 


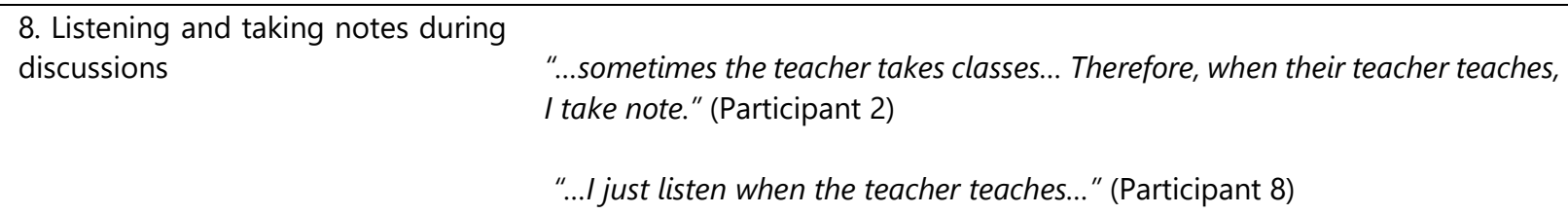

9. Translating Chavacano to their Mother Tongue
"I'll just translate his MTB modules...I'll translate it to my child in Tagalog...." (Participant 1)

"...I need to translate the lessons to Tagalog for my child to understand..." (Participant 6)

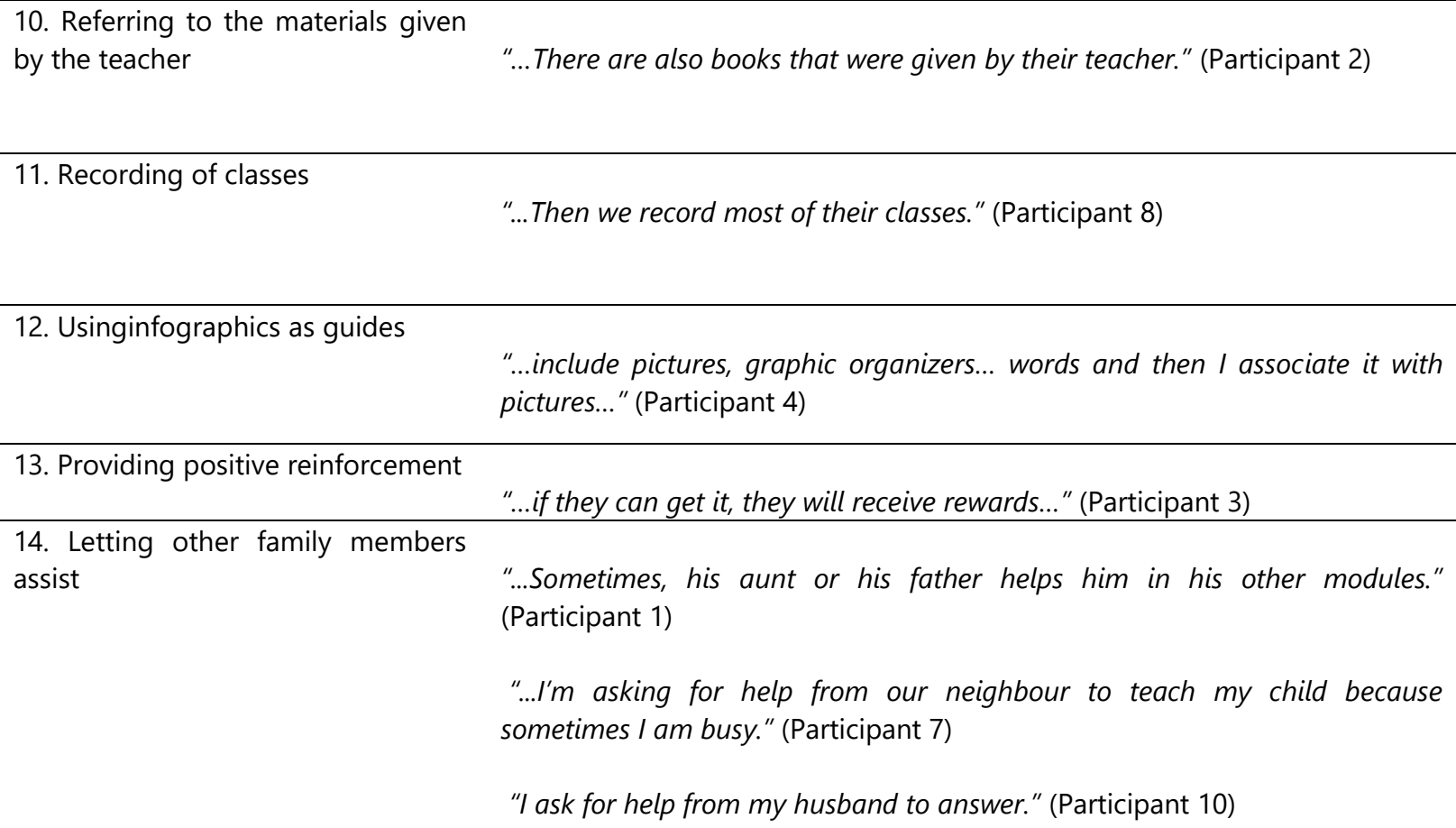

Table 2 presents the coping mechanisms of the mothers on the struggles they have encountered in assisting their child in the MT subject.

Eight (8) out of the ten (10) or $80 \%$ of the participants noted that the strategy they have done to assist their children despite the challenges that have been mentioned above is by seeking assistance from native Chavacanospeakers. The excerpts "...I first ask someone else who knows it..." and "... I really need to ask help from my friends who know how to speak Chavacano..." explain that mothers ask Chavacanospeakers whom they know to understand or let them explain what was written in the module.

The following excerpt supports this notion:

\section{Participant 4}

"...So what I do is I ask some of my friends who are Chavacano speakers... I ask my co-teachers who are teaching Mother Tongue."

The participant explained that by asking someone who is a Chavacanospeaker has been her way to know the definition and understand the contexts that are being written in the MT modules of her child. In other words, asking from a native Chavacanospeaker lets them know the definition, understand the questions and comprehend the contexts. 
Theses excerpts prove this claim:

\title{
Participant 6
}

\author{
"...I chat with my co-mothers... \\ just to ask for the definitions... \\ For example now, "debuja", \\ Before, I didn't know that the definition of this word now is "to draw".
}

\section{Participant 7}

\author{
"I really struggled... so... \\ ...or ask someone what it means. \\ I just ask questions...
}

From the excerpts above, it can be drawn that the majority or eighty percent (80\%) of the respondents are seeking assistance from a Chavacanospeaker that they know. The ground view is that nativeChavacanospeakers can give accurate definitions and explanations because they are experts in their own language. As a support, Widdowson (1994) argued that native speakers are people who own the language. In addition, Edward (2016) claimed that native speakers embody the standard and norms that are imparted in the language they speak. In other words, they have extensive understanding and wide vocabulary in their language they own and can therefore give accurate definitions if asked so. Thus, this has been the topmost strategy that is being mentioned by the participants with the reason of accuracy.

The participants also narrated that another strategy they have through is asking someone who knows how to speak and understands Chavacano, though they are not native speakers. This strategy is cited in the response of participant 7 . She mentioned that if she cannot understand what was written in the module, she asks her neighbor who knows a little of Chavacano. This has been her strategy in assisting her child in the MT subject to understand the context and be able to teach it to her child.

The following excerpt supports this claim:

\section{Participant 10}

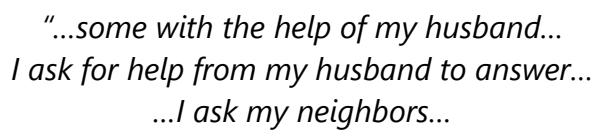

In the case of participant 10, she asks either her husband or her neighbor for the difficult words she has encountered in the module. In other words, if there are parts that she cannot understand, she immediately asks those parts to her husband or neighbor. It can be drawn that a non-native speaker who can understand and speak Chavacano can serve as an avenue to be able to assist her child in the MT subject.

Furthermore, for direct instruction and explanation, a participant mentioned that if she cannot understand what was written in the module, she immediately calls the teacher of her child to ask for definitions and clarifications. The excerpt "...l'll call their teachers to explain what it means... to know what I shall do and what I shall teach to the children..." proves the claim. Anzaldo (2021) stated that teachers must guide the parents in assisting their children at home, especially those from Kindergarten to Grade three. In similar ground, this has been the immediate strategy of the participant.

There are also translations from the module that can serve as a reference to the mothers who are the ones assisting, and this has been the strategy used by two (2) or $20 \%$ of the participants. The excerpt "...there are translations which I can look over..." states that the participant uses the translation in the module to understand the Chavacano words and instructions in the MT module. Moreover, she added that the translation is from Chavacanoto English which are written inside the parenthesis every after statement. This has served as a strategy in assisting their child's M modules.

The following excerpt is supporting this idea:

\section{Participant 9}




\title{
"There is also a translation... \\ from Chavacano to English there in the module..."
}

The participant mentioned that some MT modules have an intended part for translation and it can be used as a guide when learners are doing their modules.

Technology has also played a vital role in these difficult times. It is accessible and convenient as people can search their queries and receive an answer in just a click. Hence, this strategy has been prominent to $70 \%$ of the participants. In the excerpt "...I do research or I Google it...but in Spanish because there are no results if I search it in Chavacano...I let him watch Chavacano videos on YouTube", it can be drawn that internet, specifically Google and YouTube, became the search engines of the participant to understand the words in the module. This is also reflected in the excerpt from participant 8, she uttered "We look for it on Google...We look for it on... We watch it on YouTube". On the other hand, participants 1, 3 and 7 only utilize Google as their aid to know the definition of Chavacanowords.

This statement is being supported by the following excerpts:

\section{Participant 1}

\section{Participant 3}

\author{
"I sometimes do not understand some words \\ so I researched it... \\ research it then translate it in English \\ and I'll explain it to my child based on what I have understood. \\ For me, I will research those difficult words..."
}

"...Therefore, I have to Google it before I teach them, I'll search first for the meaning of the words.

My strategy is to search first..."

\section{Participant 7}

\author{
"I am struggling because... \\ I'll just do research... \\ I looked it up on Google..."
}

In fact, Reddy and Bubonia (2020) stated that technology offers opportunities for learners to learn at their own pace and convenience. In other words, it is the easiest and fastest way to know such queries. Thus, strategy is commonly used by the majority of the participants. Specifically, Google and You Tube had been the two noticeable applications that the mothers use as search engines (Abante, et al., 2021). Moreover, Anzaldo (2021) suggested that modular learning should be blended with online teaching for parents and children to gain more assistance from the teacher.

Continuing, $30 \%$ of the participants shared that they were still able to assist their children despite the challenges through repetitive teaching. In the excerpt "...What I did is to teach and make him understand repetitively", it can be inferred that the participant repetitively teaches the lesson for her child to understand. Since primary schoolers are not yet proficient and cannot acquire knowledge immediately (Tibon, 2020), participants do repetitive teaching for lessons to be understood.

This strategy can also be found from the excerpts of $40 \%$ of the participants. Thus, repetition of lessons enables familiarization and memorization from the end of the child. This means that learners can acquire learning through repetitive teachings of the word or lesson in the MT module.

A participant shared that she converse with her son in the Chavacanolanguage for him to practice the language and for him to eventually understand what is being written in the MT module.

This excerpt proves this idea:

\section{Participant 1}


"I speak Mother Tongue (Chavacano) to him... I train him here, even here at home, even not as part of his lecture."

The participant stated that she sometimes uses Chavacanoas the language to communicate with her child. More so, the participant shared that her child, who cannot understand Chavacano, often asks her what the meaning of the word she just said is. By this, her child will be familiar with the words being used in the conversation and be able to apply it if it appears on the module.

Further, mothers also involve themselves while their children take classes. The excerpt from participants 2 and 8; "...sometimes the teacher takes classes... Therefore, when their teacher teaches, I take note" and "... just listen when the teacher teaches", respectively, proving that the participants take time listening to their children's classes. Participant 2 elaborated that she takes note if ever there are online classes for her child to catch up the lessons if she will assist her in her modules. Thus, this strategy allows the mothers to include themselves for them to be able to understand what is being taught and to assist appropriately what is needed to be taught.

Moreover, two (2) or $20 \%$ of the participants shared the same strategy in assisting their child in their MT module, and this is by translating the words that are written in the module. The excerpts "I just translate his MTB modules...I'll translate it to my child in Tagalog...." and"...I need to translate the lessons to Tagalog for my child to understand" prove the claim. The respondents' strategy is by translating the words in the MT module to their children's MT. This strategy will help their children understand the lessons as they are being taught with the language they are most comfortable with which is their MT. On the contrary, Aquino (2012) claimed that it is crucial for learners to learn in their MT. However, translation is still being used by the participants as a strategy in assisting their child in the MT subject.

A participant also mentioned that despite her limited understanding of the Chavacanolanguage, she was still able to assist her child through the materials given by the teacher.

The following excerpt supports the claim:

\title{
Participant 2
}

"...There are also books that were given by their teacher."

The participant elaborated that there are Chavacano books that are relevant and can be used as reference for the parents and learners. These books are given by the teacher to let them look for words they do not understand and be able to teach it correctly. This idea mirrors the suggestion of Anzaldo (2021) that adequate learning materials should also be provided for additional assistance.

The excerpt "...Then we record most of their classes" presents another strategy that is being employed by a participant. Participant 8 expressed that recording of her child's classes will serve as a review and reference for her when she assists her child in the MT module. This also guides her on how and what to teach if she does not understand the words.

The challenge "modules have no pictures as guide" that was mentioned above has also an equivalent coping mechanism from a participant.

The following excerpt points the idea:

\section{Participant 4}

\author{
"...include pictures, graphic organizers... I include \\ words and then I associate it with pictures... \\ So for example, I flash a picture and I let her familiarize it."
}

The participant explained that if there are no pictures in the module, she prints or shows pictures of the intended word. She uses this technique for her child to familiarize and understand the word written in the module. She also added that pictures must be included since grade 1 learners are virtual learners. Therefore, her technique is by inculcating infographics such as pictures and graphic organizers for her child to understand the MT module. 
With regard to the challenge "managing child's behavior", there is also a tactic being shared by a participant in this concern.

This excerpt indicates agreement to the claim:

\title{
Participant 3
}

\author{
"...if they can get it, \\ they will receive rewards... \\ If there are no rewards in the end, \\ they will not really focus."
}

The participant explained that for her to handle her child's behavior she gives positive reinforcement through rewards. The reason is that when she sets a reward, her child behaves well. It is important to note that children's challenging behavior could have negative impacts on their learning (Smith \& Granja, 2017). Therefore, there must be remedies for this to be managed. More so, the reward is also applicable if the child can answer or does well while she assists her child in the MT subject.

Lastly, three (3) out of the ten (10) or 30\% of the participants shared that sometimes they let the other family members assist their child. The excerpts "...Sometimes, his aunt or his father helps him in his other modules" and "I ask help from my husband to answer" prove the claim. Participants 1 and 10 shared that they let either their husband or aunt to assist their child in their MT module. Though they are busy, a child must have someone else to assist him. As a support, Alicamen and Abadiano (2020) stated that learners who are still in primary education need regular adult assistance and therefore dynamic support from family is needed (Colombo, 2006).

This excerpt supports the idea:

\section{Participant 7}

\author{
"...I'm asking for help from our neighbour to teach my child \\ because sometimes I am busy."
}

This strategy is contrary to the challenge mentioned above about the implementation of time management. Participants look for the other members of the family to assist their child in the MT subject if they become busy with their work. The study of Allmendinger (2020) found out that mothers prioritize their work more than child care even this time.

\section{Conclusion}

This current study shed some light on mothers', who do not speak the MT, struggles and coping mechanisms in assisting their child in the MT subject. The in-hand study found out that difficulty in understanding Chavacanowords on the module, difficulty in comprehending instructions on the module, lack of educational pictures, difficulty in translating to the child's Mother Tongue, difficulty in facilitating learning, difficulty managing child's behavior and struggle in implementing time management became their primary struggles in assisting their child in the MT subject. Hence, mothers were still able to assist their child despite of these challenges through seeking assistance from native Chavacanospeakers, seeking assistance from someone who has more knowledge in Chavacano, seeking assistance from the teacher, using the translation provided as reference, searching on the internet, repetitive teaching, practice through conversation, involvement during discussions, translating Chavacano to their mother tongue, materials from the teacher, recording of classes, use of infographics, providing positive reinforcement and letting family members to assist. The general reason for these challenges is that mothers have different MTs and therefore cannot comprehend and at the same time assist their child in their MT subject. The findings of this study can further contribute to the insisting and probable development of strategies by the Department of Education (DepEd) with regard to Mother Tongue Based -Multilingual Education (MTB-MLE) in modular learning. The DepEd should consider the idea of including translations to English in the MT subject. This is the most convenient and immediate source for mothers who also do not speak the MT in assisting their child. Also, they can distribute Chavanobooks or dictionaries. Moreover, mothers who do not speak the MT can apply the shared coping mechanisms while they assist their children. With the compelling results, this study recognizes that the participants' struggles and coping mechanisms while assisting their child in the MT subject do not generalize the whole experiences of mothers not speaking the MT. Therefore, future studies are encouraged to conduct in the same field as an effort to generalize the result of this study by taking different views by concerning a great number of participants from other cities and regions with different backgrounds and ethnicities.

\section{Recommendation}


Numerous studies had already been conducted relative to modular learning and struggles in the Mother Tongue BasedMultilingual Education. Thus, future studies in the same context are highly recommended. Since the current study focused on struggles and coping mechanisms of mothers not speaking the MT in the localization of Zamboanga City only, future research may explore on determining struggles and coping mechanisms of mothers not speaking the MT in other cities, or with respect to ethnicity. Future studies on this ground will contribute to the development and implementation of possible solutions from respective government agencies in addressing the struggles that are encountered by mothers who do not speak the MT in assisting their child in the current modular learning.

\section{References}

[1] Aaronson, D., Barrow, L., \& Sander, W. (2007). Teachers and student achievement in the Chicago public high schools. Journal of Labor Economics, 25, 95-135.

[2] Abante, A., Cruz, R., Guevarra, D., Lanada, M., Macale, M., Roque, M., . . Cabrera, W. (2021). A comparative analysis on the challenges of online learning modality and modular learning modality: A basis for training program. International Journal of Multidisciplinary Research and Analysis, 4(4), 463-476. doi:10.47191/ijmra/v4-i4-17

[3] Alicamen, D., \& Abadiano, , M. (2020). Parents as study buddy in the new normal of teaching: A grounded theory. Phsychology and Education, 57(9), 5434-5447.

[4] Alieto, E., Devanadera, A., \& Buslon, J. (2019). Women of K-12: Exploring teachers' cognition in language policy implementation. Asian EFL Journal, 24(4.1), 143-162.

[5] Allmendinger, J. (2020). Zurück in alte Rollen. Corona bedroht die Geschlechtergerechtigkeit. WZB Mitteilungen: Issue 168. Retrieved from WZB Mitteilungen.

[6] Anzaldo, G. (2021). Modular Distance Learning in the new normal education amidst Covid-19. International Journal of Scientific Advances, 3, 263-266. doi:10.51542/ijscia.v2i3.6

[7] Aquino, L. (2012). The Effects of Bilingual Instruction on the Literacy Skills of Young. ELTWorldOnline.com.

[8] Bernardo, J. (2020, July 30). Modular learning most preferred parents: DepEd. Retrieved from ABS-CBN News: https://news.abscbn.com/news/07/30/20/modular-learning-most-preferred-by-parentsdeped

[9] Brandsma, H., \& Knuver, A. (1989). Pupils' sense of well-being and classroom educational factors. In B. Creemers, T. Peters, \& D. Reynolds, School effectiveness and school improvement: Proceedings of the second international congress (pp. 131-140). Lisse: Swets \& Zeitlinger.

[10] Bujard, M. (2020, September 22). Eltern werden in der Corona-Krise. Zur Improvisation gezwungen. Retrieved from Bundesinstitut für Bevölkerungsforschung: https://www.waxmann.com/?elD=texte\&pdf=42310penAccess03.pdf\&typ=zusatztext

[11] Bünning, M., Hipp, L., \& Munnes, S. (2020, September 03). Erwerbsarbeit in Zeiten von Corona, WZB Ergebnisbericht. Retrieved from Wissenschaftszentrum Berlin für : https://www.econstor.eu/handle/10419/216101

[12] Choi, N., Kang, S., Cho, H., \& Sheo, J. (2019). Promoting young children's interest in learning English in EFL context: The role of mothers. Education Sciences, 9(1), 46.

[13] Colombo, M. (2006). Building school partnerships with culturally and linguistically diverse families. Phi Delta Kappan, 314-318.

[14] Cummins, J. (2000). Language, power, and pedagogy: Bilingual children in the crossfire. Clevedon, UK: Multilingual Matters.

[15] Dangle, Y., \& Sumaoang, J. (2020, November 29). 3rd International Conference on Advanced Research in Teaching Education. Retrieved from The Implementation of Modular Distance Learning in the Philippines Secondary Public Schools: https://www.dpublication.com/wpcontent/uploads/2020/11/27-427.pdf

[16] De Villa, J., \& Manalo, F. (2020). Secondary teachers' preparation, challenges, and coping mechanism in the pre -implementation of distance learning in the new normal. IOER International Multidisciplinary Research Journal, 2(3), 144-154.

[17] Dekker, D., \& Young, C. (2005). Bridging the gap: The development of appropriate educational strategies for minority language communities in the Philippines. Current Issues in Language Planning, 6, 182-199.

[18] Dela Cruz, S., Deran, J., Alieto, E., Abdon, M., Rillo, R., \& Lucas, I. (2020). Cognition toward the Mother Tongue, attitude toward English, Chavacano, and Filipino: A structural equation modeling approach with bootstrap analysis. The Asian ESP Journal, 16(1.2), 6-28.

[19] Denzin, N., \& Lincoln, Y. (1994). Introduction: Entering the field of qualitative research. In N. Denzin, \& Y. Lincoln, Handbook of qualitative research. Thousand Oaks: CA: Sage.

[20] Edwards, J. (2016). Defining 'native speaker' in multilingual settings: English as a native language in Asia. Journal Of Multilingual And Multicultural Development, 1-15. doi:http://www.tandfonline.com/action/showCitFormats?doi=10.1080/01434632.2016.1257627

[21] FlipScience. (2020, October 5). 'Tagapagdaloy': How Filipino parents can help ensure successful modular distance learning. Retrieved from FlipScience - Top Philippine Science News and Features for the Inquisitive Filipino: https://www.flipscience.ph/news/featuresnews/tagapagdaloy-modular-distance-learning/

[22] Francisco, W., Leduna, N., Librado, K., Nunez, M., Pabraquel, M., Deran, J., . . Ramos, S. (2020). Substituting English with a local language: Examining parents' belief toward Chavacano as language of instruction. Asian EFL Journal Research, 27(1), 177-195.

[23] Harding, J. (2018). Qualitative data analysis: From start to finish. SAGE Publications Limited.

[24] Jellen, J., \& Ohlbrecht, H. (2020). Parenthood in a crisis: Stress potentials and gender differences of parents during the Corona pandemic. International Dialogues on Education, 7, 44-51.

[25] Kane, T., \& Staiger, D. (2008). Estimating teacher impacts on student achievement: An experimental evaluation. Cambridge: National Bureau of Economic Research.

[26] Lewis, P., Simons, G., \& Fennig, G. (2013). Ethnologue: Languages of the World. Dallas, Texas: SIL International. Retrieved from Dallas, Texas: SIL International.

[27] Li, F., Qi, J., Wang, G., \& Wang, X. (2014). Traditional classroom vs e-learning in higher education: Difference between students' behavioral engagement. $\mathrm{U} E T, 9(2)$.

[28] Mazrekaj, D., \& De Witte, K. (2019). The effect of modular education on school dropout. British Educational Research Journal, 46(1), 92-121. 
[29] Mazuru, M., \& Nyambi, O. (2012). Celebrating Africana motherhood: The Shona proverb and the familial and social roles of mothers as first teachers, cultural bearers and co-partners. International Journal of Asian Social Science, 2(5), 596-601.

[30] Moules, N., Norris, J., Nowell, L., \& White, D. (2017). Thematic analysis striving to meet trustworthiness criteria. Internationa Journal of Qualitative Method, 6, 1-13.

[31] Nolasco, R., Datar, F., \& Azurin, A. (2010). Starting where the children are: A collection of essays on Mother tongue-based multilingual education and language issues in the Philippines. Diliman, Quezon City: 170+ Talaytayan MLE.

[32] Nugroho, A., llimiani, D., \& Rekha, A. (2020). EFL teachers' challenges and insights of online teaching amidst global pandemic. Journal of English Language Literature and Teaching, 4(3), 277-291.

[33] Reddy, S., \& Bubonia, J. (2020). Technology in education: Learning opportunities for teachers and students. Journal of Family and Consumer Sciences, 112(1), 46-50. doi:10.14307/JFCS112.1.46

[34] Rockoff, J. (2004). The impact of individual teachers on student achievement: Evidence from panel data. American Economic Review, 94(2), 247-252.

[35] Senthilkumar, S., \& Kumari, K. (2020). Impact of Coronavirus on education: Stay away from schools. Alochana Chakra Journal, 9(6), 34403447.

[36] Siv, S., \& Kim, M. (2019). How do multicultural family mothers perceive child's English education? English Teaching, 74(3), 161-185.

[37] Smith, S., \& Granja, M. (2017). The Voices of Maine's Early Care and Education Teachers Children with Challenging Behavior in Classrooms and Home-based Child Care. Retrieved from National Center for Children in Poverty: https://files.eric.ed.gov/fulltext/ED590456.pdf

[38] Tibon, J. (2020). The New Normal in Basic Education. Retrieved from https://www.researchgate.net/deref/https\%3A\%2F\%2Fwww.lexology.com\%2Flibrary

[39] Tupas, R. (2015). Inequalities of multilingualism: Challenges to mother tongue-based multilingual education. Language and Education, 29(2), 112-124.

[40] Tupas, R., \& Martin, I. (2016). Bilingual and Mother Tongue-Based Multilingual Education in the Philippines. In R. Tupas, \& I. Martin, 10.1007/978-3-319-02324-3_18-1.

[41] Widdowson, H. (1994). The Ownership of English. TESOL Quarterly, 28, 377-388. 